\title{
Advances in endoscopic resection: a review of endoscopic submucosal dissection (ESD), endoscopic full thickness resection (EFTR) and submucosal tunneling endoscopic resection (STER)
}

\author{
Ishita Dalal $^{1}$, Iman Andalib ${ }^{2}$ \\ ${ }^{1}$ Department of Gastroenterology and Hepatology, Rutgers Robert Wood Johnson, New Brunswick, New Jersey, USA; ${ }^{2}$ Department of \\ Gastroenterology and Hepatology, Mount Sinai South Nassau, Oceanside, New York, USA \\ Contributions: (I) Conception and design: Both authors; (II) Administrative support: None; (III) Provision of study materials or patients: None; (IV) \\ Collection and assembly of data: Both authors; (V) Data analysis and interpretation: Both authors; (VI) Manuscript writing: Both authors; (VII) Final \\ approval of manuscript: Both authors. \\ Correspondence to: Iman Andalib, MD. Director of Surgical Endoscopy, Mount Sinai South Nassau, One Healthy Way, Oceanside, NY 11572, USA. \\ Email: imanandalib@gmail.com.
}

\begin{abstract}
Subepithelial lesions are often detected incidentally in patients undergoing an endoscopy. They are common tumors of the gastrointestinal (GI) tract which can originate from different layers of the GI tract wall. These lesions can be further classified based on GI layer of origin and unique histochemical staining. While most are benign and asymptomatic, some of these lesions have malignant potential with distant metastases. However, current diagnostic modalities including endoscopy with biopsy or endoscopic ultrasound with fine needle aspiration are not always reliable. In addition, management of these lesions has historically involved surgical resection via open or laparoscopic approaches. In recent years, with advancement in endoscopic techniques and improvement in endoscopists' skills, less invasive procedures such as endoscopic submucosal dissection (ESD), endoscopic full thickness resection (EFTR) and submucosal tunneling endoscopic resection (STER) have been developed and now are being used by endoscopists worldwide. Upon reviewing the literature, multiple studies have shown the advantages of these endoscopic techniques when compared with surgical treatment. As a result, there has been a dramatic shift towards minimally invasive endoscopic procedures for the management of these subepithelial lesions. In this review article, we will discuss these endoscopic resection techniques in detail, their safety and efficacy, as well as comparison studies to other therapeutic modalities.
\end{abstract}

Keywords: Subepithelial lesions; endoscopic submucosal dissection (ESD); endoscopic full thickness resection (EFTR); submucosal tunneling endoscopic resection (STER)

Received: 20 January 2020; Accepted: 21 May 2020; Published: 25 April 2022.

doi: $10.21037 / \operatorname{tgh}-2020-10$

View this article at: http://dx.doi.org/10.21037/tgh-2020-10

\section{Introduction}

Subepithelial lesions are common tumors that arise from within the wall of the gastrointestinal (GI) tract. They can involve the muscularis mucosa, submucosa, or muscularis propria. Most are incidental and usually small and benign. However, at times they can be symptomatic and lead to bleeding or obstruction. Up to $15 \%$ of the lesions may also be malignant (1). Gastrointestinal stromal tumors (GISTs) are one example of these subepithelial lesions. Even though these lesions are mostly considered to be benign, all GISTs can potentially become malignant. Therefore, they require long-term surveillance. Diagnosis of these lesions with biopsies or endoscopic ultrasound with fine needle aspiration (EUS-FNA) is not always reliable so developing new therapeutic approaches for management of these lesions has become necessary. Due to their unpredictable 
malignant potential and need for long-term surveillance, elective resection can be offered to most patients.

In the past, the primary method for resecting these lesions was via open or laparoscopic surgery. However, in recent years, with advancement in endoscopic techniques, less invasive endoscopic procedures such as endoscopic mucosal resection (EMR) and endoscopic submucosal dissection (ESD) have been developed and become increasingly common approaches for removing most of these lesions. The primary goal for removal of these types of lesions is complete removal with clear resection margins. EMR is limited by inability to remove lesions en bloc when lesions are larger $>20 \mathrm{~mm}$ or in lesions that cannot be lifted properly. ESD allows the endoscopist to overcome those limitations, allowing en bloc resection. However, there is higher risk of iatrogenic perforations for lesions that originate from the deeper layers of the muscularis propria or have significant fibrosis. Therefore, these treatments are not as ideal. As a result, endoscopic full thickness resection (EFTR) has emerged as a new and viable treatment options in selected patients. Multiple studies have compared the safety and efficacy of these endoscopic techniques with surgery. Endoscopic removal has several advantages such as an intact stomach after tumor resection and shorter hospital stay compared to surgery (2-4).

In this article, we will review the advancements in the endoscopic resection techniques including ESD, EFTR and submucosal tunneling endoscopic resection (STER).

\section{ESD}

\section{Technique}

ESD is an endoscopic technique developed in the mid1990's in Japan to resect early stage GI tumors (5). It is defined as an endoscopic resection technique that specifically dissects the tissue over muscularis propria using an electrosurgical knife (5-10). It is performed in several steps. First, the margins of the lesions are marked $5-10 \mathrm{~mm}$ from the lateral edge by cautery (Figure 1A). Second, the submucosal injection is used to lift the lesion from the muscularis propria. This is followed by creating an incision around the perimeter of the lesion, and dissecting the lesion from the deeper layers using specialized electrosurgical knives (Figure 1B,1C). The defect is then closed using clips or a suturing device (Figure 1D). Finally, the lesion is removed entirely (Figure 1E).

\section{Safety and efficacy}

Over the last decade, with more experience and new advances in endoscopic techniques, ESD has become more established in the United States. It provides an opportunity to remove both mucosal and submucosal lesions en bloc when they may be too large for removal with EMR or when they are at higher risk for involving cancer but low risk for lymph node metastases.

Multiple studies and meta-analyses have shown benefit in treatment of early gastric cancer but it has also been used in colon, esophagus, gastroesophageal junction, and duodenum (5,6,11-16). Meta-analysis by Cao et al. (11), showed that when compared with EMR, ESD was associated with higher en bloc and curative resection rates along with lower rates of recurrence.

As mentioned before, multiple studies have evaluated the efficacy and safety of ESD for gastric lesions. He et al. (12) reported ESD of 145 gastric subepithelial lesions arising from the muscularis propria and complete resection was obtained in $92 \%$ of lesions. Pimentel-Nunes et al. showed that out of 162 patients undergoing endoscopic resection of gastric neoplasia, resection was feasible in $97 \%$ with en bloc and R0 resection rates of $85 \%$ (94\% ESD vs. 61\% EMR; $\mathrm{P}=0.001)$ and $81 \%(91 \%$ ESD vs. $54 \%$ EMR; $\mathrm{P}<0.001)$, respectively. They followed the patients for up to 3 years with long term curative resection rate of $88 \%$ and only $7 \%$ recurrence (17).

Other studies have compared ESD with surgery for management of early gastric cancer as well. In a recent meta-analysis, which included a total of 18 studies, ESD was associated with lower cost, faster recovery and better quality of life when compared to surgery. However, ESD had lower rate of curative resection [odds ratio $(\mathrm{OR})=0.06,95 \% \mathrm{CI}$ : $0.01,0.27, \mathrm{P}=0.002]$, and higher rate of local recurrence [OR $=5.42,95 \%$ CI: 2.91, 10.11, $\mathrm{P}<0.00001]$ (18).

ESD has also been used in the treatment of early esophageal cancer. Its superiority over EMR in terms of en bloc resection and curative resection have been reviewed in multiple studies (14,19-21). However, one concerning complication would be development of stricture post ESD since it involves deeper dissection. In a multicenter study that was published in 2017, ESD for treatment of HGD or esophageal adenocarcinoma had a $\mathrm{R} 0$ resection, curative and stricture rate of $76 \%, 70 \%$ and $15 \%$ (22), respectively. Another study showed a stricture rate of $10 \%$ post ESD (23).

Finally, ESD has also been used for resection of colorectal 

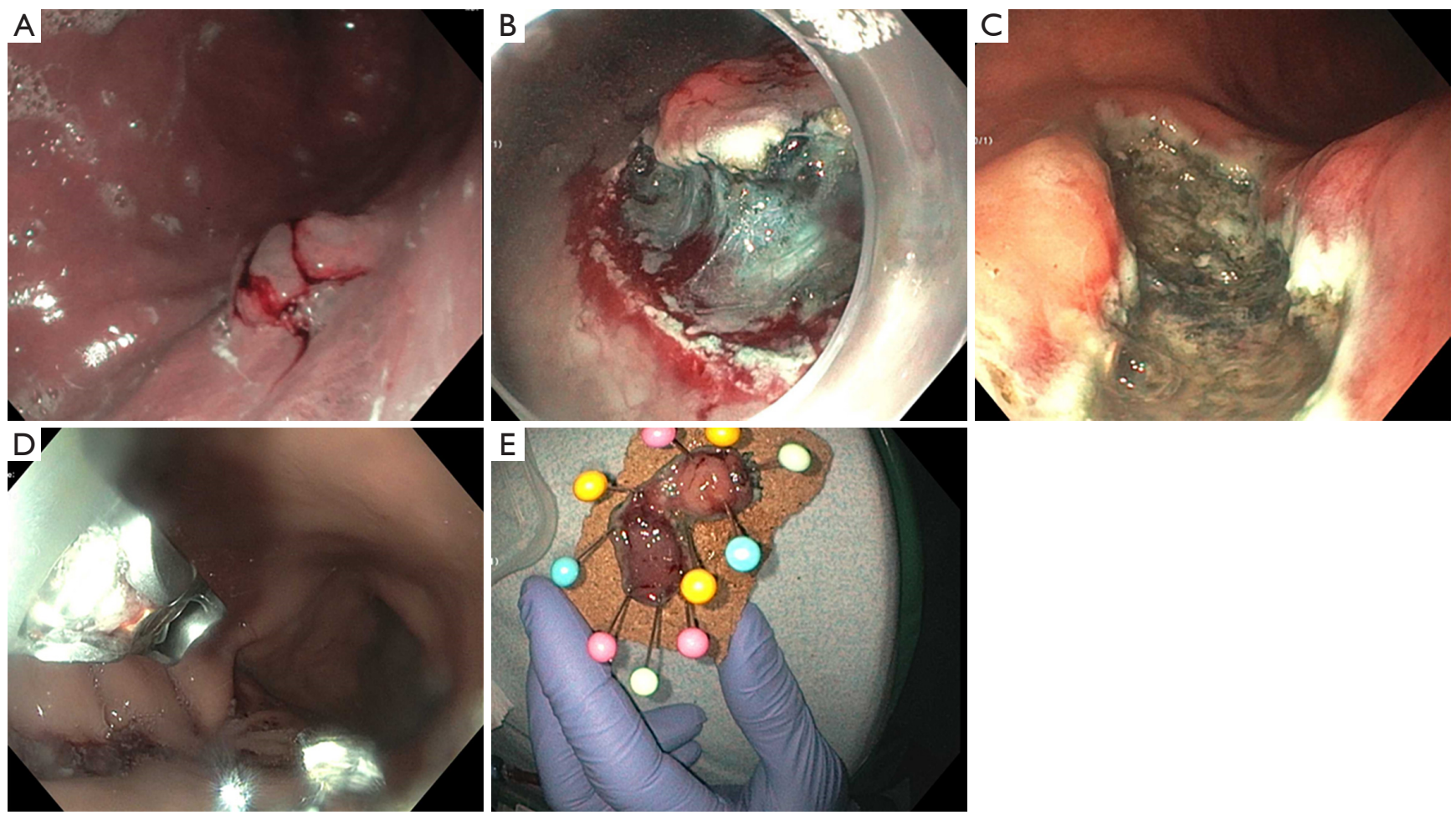

Figure 1 Endoscopic submucosal dissection. (A) Submucosal lesion noted in the gastric body; (B) lifting and submucosal dissection of the lesion; (C) gastric defect after complete resection; (D) closure of the defect with endoscopic suturing; (E) submucosal lesion post removal.

tumors especially in Asian countries. Colorectal ESD can be technically challenging, with a higher complication rate due to the burdensome maneuverability of the colon and thin wall of the colonic mucosa. As a result, it has been adopted more slowly in western countries. However, this procedure has become more popular throughout recent years with more studies evaluating the safety of colorectal ESD as well as improvement in endoscopists' skills. In 2016, Akintoye et al. published a large meta-analysis including over 13,000 patients who underwent colorectal ESD and they were able to show that endoscopic en bloc and curative resection rates were $92 \%$ (95\% CI: 90-94\%) and $86 \%$ (95\% CI: 80-90\%), respectively (24).

However, ESD has some disadvantages including higher risk of bleeding, perforation, length of procedure time and the requirement of a skillful operator. Bleeding is the most common adverse event of this technique ranging from $1 \%$ to $45 \%$ and average rates of $~ 10 \%$ in larger series (25-27). Post procedural or delayed bleeding has been reported in up to $13.9 \%$ of patients (25). Perforation rates during ESD have been reported in the range of $4 \%$ to $10 \%$ (26); however. most of these perforations can be managed endoscopically using hemoclips, over-the-scope clips (OTSCs) and/or endoscopic suturing devices (10).

\section{EFTR}

EFTR is most useful in cases involving lesions that arise from the muscularis propria, may have significant fibrosis, and often in locations difficult to assess or are high risk (28-31). This procedure involves resection of the lesion followed closure of the wall defect using clips or endoscopic suturing. This would potentially make it more challenging than ESD since it requires more extensive resection and there is increased risk of not being able to close the defect. Two general approaches to EFTR have been described, nonexposed and exposed.

\section{Non-exposed EFTR}

\section{Technique}

Nonexposed EFTR is considered to be more similar to surgical rather than endoscopic techniques. It uses an OTSC and involves suctioning or retracting the lesion 
into the cap and deployment of the clip around the lesion. This allows for serosa to serosa apposition which isolates the lesion. Subsequently, the endoscopist can proceed with resection above the clip $(32,33)$. Nonexposed technique can be considered advantageous when compared to other approaches because a large defect is not created, lowering the risk of contamination into peritoneal cavity or perforation. A submucosal injection may be used beforehand, but is not needed. The resection may be done with electrosurgical snare or knife depending on the lesion and difficulty (16,32-36).

Full thickness resection device (FTRD) is dedicated for EFTR. The FTRD ideally allows for a one-step EFTR. The device includes an applicator cap with a 14-mm over the scope clip and an integrated 13-mm electrosurgical snare which is preloaded in the tip of the cap. Prior to use, the lesion is marked with argon plasma coagulation. The cap, which features a clip release thread, is pulled in a retrograde fashion through the working channel of the endoscope and fixed onto a hand-wheel mounted on the working-channel port of the endoscope. The lesion is retracted into the cap, and the clip is deployed by turning the hand-wheel. Finally, using an electrosurgical snare, the lesion is resected above the clip.

\section{Safety and efficacy}

One multicenter study showed that in 181 lesions (adenomas, early adenocarcinomas, and subepithelial lesions) resected with the FTRD, the success rate was $89.5 \%$, with R0 resection rate of $76.9 \%$. The $\mathrm{R} 0$ rate was higher in smaller lesions; $81.2 \%$ in lesions smaller than $2 \mathrm{~cm}, 58.11 \%$ in lesions larger than $2 \mathrm{~cm}$. When looking specifically at the subepithelial lesions, the $\mathrm{R} 0$ resection rate was $87 \%$. There were 18 adverse events; including abdominal pain, bleeding, appendicitis, post polypectomy syndrome, enterocutaneous fistula formation and six perforations. Five of these perforations occurred immediately post resection due to clip not being released from cap appropriately and resection of the lesion subsequently occurred prior to closure. Four perforations were able to be closed endoscopically during the same case and one patient needed surgery. The last perforation occurred three days post resection and was thought to be secondary to thermal damage that may have been caused by entrapment of the clip into snare because a conventional snare was used (37). While initial studies primarily established its use in colorectal lesions, a recent smaller retrospective analysis of 20 patients that underwent EFTR with FTRD of the duodenum for adenomas, subepithelial tumors, and $\mathrm{T} 1$ adenocarcinoma found success in $85 \%$ of patients with an $\mathrm{R} 0$ resection rate of $63.2 \%$ (38), implying a possible benefit in upper GI lesions although further studies must be done.

\section{Exposed EFTR}

With exposed EFTR, resection is done first, followed by closure of the defect. There is temporary exposure of the lumen during this approach. It is primarily for lesions $<3 \mathrm{~cm}$, due to difficulty with extraction for lesions larger than $3 \mathrm{~cm}$ and also difficulty with closure (39). This approach is further divided into a non-tunneled $v s$. tunneled technique.

\section{Non-tunneled exposed EFTR}

\section{Technique}

Non-tunneled exposed EFTR, or standard EFTR, is similar to ESD. The lesion is marked with electrocautery (Figure $2 A$ ) and the submucosal layer is injected with a lifting solution agent. Circumferential dissection within submucosal layer is done to allow en bloc resection. The dissection is then continued through the muscularis propria around the lesion (Figure 2B). The defect is subsequently closed (Figure 2C).

\section{Safety and efficacy}

Many of the studies evaluating removal of subepithelial lesions using EFTR have shown success with complete resection with no major complications reported. Majority of the lesions in these studies were GISTs and leiomyomas. A systematic review by Jain $e t$ al. examined six studies which showed an average rate of success of approximately $96.8 \%$. The lesions ranged in size from 1.2 to $3.4 \mathrm{~cm}$. There was no reported mortality and a low rate of complications overall, notably localized peritonitis, abdominal distension, fevers, all of which were able to be managed conservatively (40).

A study by Huang et al. reported 35 gastric submucosal tumors arising from the muscularis propria with a $100 \%$ complete resection rate. Five patients required decompression due to significant pneumoperitoneum post procedure. However, contrast examination three days post procedure showed no extravasation in any patients and no significant bleeding, peritonitis or abdominal abscess occurred was noted. There was no residual lesion or recurrence in the 6-month follow up period (30). Furthermore, a retrospective study by Yang et al. examined 41 gastric tumors that were an average of $1.6 \mathrm{~cm}$, primarily located in the body and fundus. R0 resection was achieved 

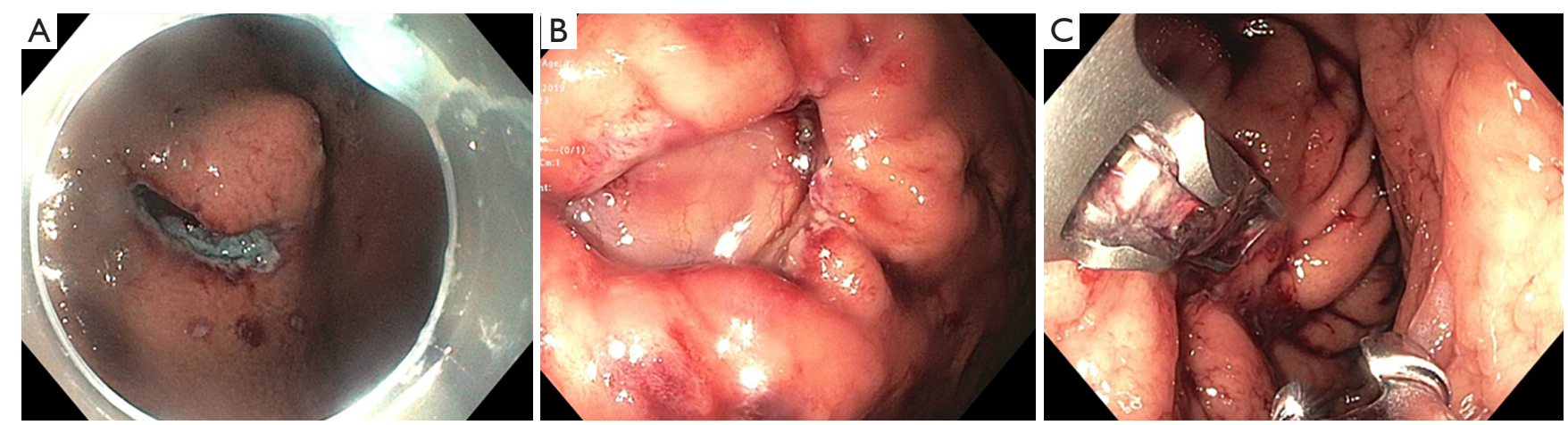

Figure 2 Endoscopic full thickness resection. (A) Submucosal lesion noted in the gastric fundus and marked; (B) circumferential dissection of lesion leaving a defect; (C) closure of defect with suturing device.

in all cases. Pneumoperitoneum was seen in 26 patients but was conservatively managed with no cases of bleeding, peritonitis, or abdominal abscess noted. Mild procedural complications such as abdominal pain, nausea and vomiting, pharyngalgia, and fever were all self-limiting and resolved within 3 days (41).

These techniques were also compared to existing surgical procedure to determine efficacy. Joo et al. compared surgical resection of GIST in the upper GI tract with endoscopic resection. The endoscopy group had smaller tumor size $(2.3 \mathrm{~cm}$ in the endoscopic group $v s .5 .1 \mathrm{~cm}$ in the surgical group), along with shorter procedure times and hospital stays. The recurrence rate was not significantly different between the two group during the follow up period of 45.5 months (2.2\% vs. $5.0 \% ; \mathrm{P}=0.586)$ (42). Another study comparing therapeutic outcomes of EFTR vs. laparoscopic approach with GISTs also showed favorable results in lesions $<2 \mathrm{~cm}$. They recorded $100 \%$ resection rates, with lower mean procedure times, intraoperative blood loss, hospital stays and time until food intake. Complications included perforations created during EFTR which were all successfully closed and four episodes of intraoperative bleeding with successful hemostasis during the procedure (43).

\section{Closure techniques}

There are a variety of techniques described for closure of the lesion, including through the scope clips, over the scope clips, or endoscopic suturing (16,34). The closure approach is determined by the lesion and size of defects, but also dependent on experience level of the operator and availability of the devices. Some of these closure techniques are described below.

Hemoclips can be used alone for the closure of defects.
There are several clipping devices with different prongdiameters that are available in the market. Zhou et al. (44) reported the safety and efficacy of resection of the gastric submucosal tumors with EFTR and closure with clip. The complete resection rate was $100 \%$ with an average size of $2.8 \mathrm{~cm}$. Patients were followed for 6-24 months, with a mean follow up period for 8 months; no residual lesions or recurrence was seen during this time. No cases had severe complication such as bleeding, abscess formation, peritonitis, or death (44). However, due to the clips' width, low closure force and lack of deep tissue capture, clipping alone is not always effective for large defects and it may only be sufficient for defects less than $30 \mathrm{~mm}$ in diameter (45).

With advancements in endoscopic tools, combined application of clips and endoscopic loops have been used to safely and effectively close large post-resection defects. Ye et al. (46) reported 51 patients who underwent EFTR for resection of gastric subepithelial lesions with subsequent closure with clips and endoloop. They used multiple clips in a side-to-center manner to close large defects. Subsequently, an endoloop was placed to entrap and constrict all clips together for defect closure. The clinical success was $98 \%$. Complications were limited to minor bleeding that was controlled endoscopically and no serious adverse effects were noted (46).

There are other closure devices that can be used for larger defects. The OTSC (Ovesco, Tübingen, Germany) comprises of an applicator cap, a nitinol clip, and a hand wheel. It allows a stronger closure because it grasps more tissue compared to traditional clips. Endoscopic suturing devices are also commonly used for closure of these defects. The OverStitch device (Apollo Endosurgery, Austin, Texas, USA) is one of the approved endoscopic suturing devices in 
the United States (47-49).

Although full thickness resection followed by closure can be effective, there are some challenges associated with it. The large defects may be difficult to close, loss of insulation to maintain proper operative field, tumor seeding into the abdominal cavity, and/or spillage of GI content into the abdominal cavity (34). Other events related to air in the peritoneal space such subcutaneous emphysema, pneumomediastinum, and pneumoperitoneum may also occur due to damage to the mucosal wall, but are not concerning adverse events unless they are symptomatic. Risk is minimal due to the increased use of $\mathrm{CO}_{2}$ during procedures and its rapid absorption $(16,34)$.

\section{Tunneled exposed EFTR: STER}

\section{Technique}

Tunneled resection was inspired by natural orifice transluminal endoscopic surgery (NOTES) and peroral endoscopic myotomy (POEM) for achalasia. In POEM, an incision is made in the esophageal mucosa to create a tunnel that crosses the gastroesophageal junction, and thus providing a submucosal space to work in. It was this technique that ultimately inspired the development of STER (50).

A tunneled approach limits the amount of air and contents outside the lumen of the GI tract. The goal of STER is to allow resection of lesions while maintaining the mucosal layer by creating a submucosal space prior to resection. As a result, the best locations for STER include relatively straight and tubular structures such as the esophagus or gastric cardia (16). However, even though it may be technically more difficult, STER can even be used in sites such as the stomach and rectum without an increase in adverse events (49-52). It is primarily used in lesions $<4 \mathrm{~cm}$ in diameter. Larger lesions, as with other procedures, are difficult to retrieve and may limit visualization during the procedure (31).

A study by Tan et al. compared the removal of larger lesions with STER when compared to video-assisted thoracoscopic surgery (VATS) and showed comparable efficacy between both groups, however those within the STER group were noted to have shorter procedure times and hospital stays, lower costs, and less decrease in hemoglobin level when compared to the surgical group (53).

During the procedure, the submucosal lesion is identified (Figure $3 A$ ), then a submucosal injection is done using a lifting agent. An incision is then made with some distance, approximately $5 \mathrm{~cm}$, from the lesion. The submucosal layer is then dissected towards the lesion and a dye such as indigo carmine methylene blue (Figure $3 B$ ) is used to better differentiate the submucosal and muscular layers and limit injury. Dissection (Figure 3C) should continue at least $2 \mathrm{~cm}$ past the distal end of the lesion $(52,54)$; after the lesion is extracted, the defect is closed with clip placement or endoscopic suturing (Figure 3D) (55). The risk of developing mediastinitis or peritonitis is decreased because the mucosa remains intact (55).

\section{Safety and efficacy}

In a large meta-analysis with Lv et al. of 28 studies describing the use of STER in upper GI lesions, there was a complete resection rate of $97.5 \%$ and en bloc rate of $94.6 \%$ with a generally low rate of adverse events. Subcutaneous emphysema/pneumomediastinum was seen in $14.8 \%$, but prevalence of perforation was only 5.6\% (56). Long-term implications were described in a retrospective study by Chen et al., in which 180 patients were followed for approximately 3 years and none of these patients had recurrence or distant metastasis (57). Based on these studies, STER is a safe and effective method for the removal of lesions originating from the muscularis propria. It is contraindicated in lesions where the mucosa is ulcerated or lesions with irregular borders because they may be difficult to resect. Additionally, with lesions with deep involvement of the muscularis propria, there is increased risk of adverse events such as perforation, fistula formation, and infection (55-59).

Both standard EFTR and STER are safe and feasible options for removal of submucosal lesions. In one study by Tan et al. comparing EFTR and STER for treatment of gastric GIST, there was no difference seen when evaluating complication rate, resection rate, length of procedure or tumor size. The only difference was seen when looking at time and number of clips for sutures, with EFTR requiring longer suture times and more clips than STER (60). Another study by Duan et al. compared STER and EFTR in patients with gastric fundal submucosal lesions and also showed similar findings with shorter suture times and fewer number of clips in the STER group (61). Both studies also showed decreased nothing per oral (NPO) period during hospitalization with the STER group. The studies highlighted that STER maintains the mucosal layer, allowing for better wound healing and decreased risk of GI tract leakage. In the study by Tan et al., 4 patients in the EFTR group had abdominal pain due to leakage into the abdominal cavity while only one patient in the STER 

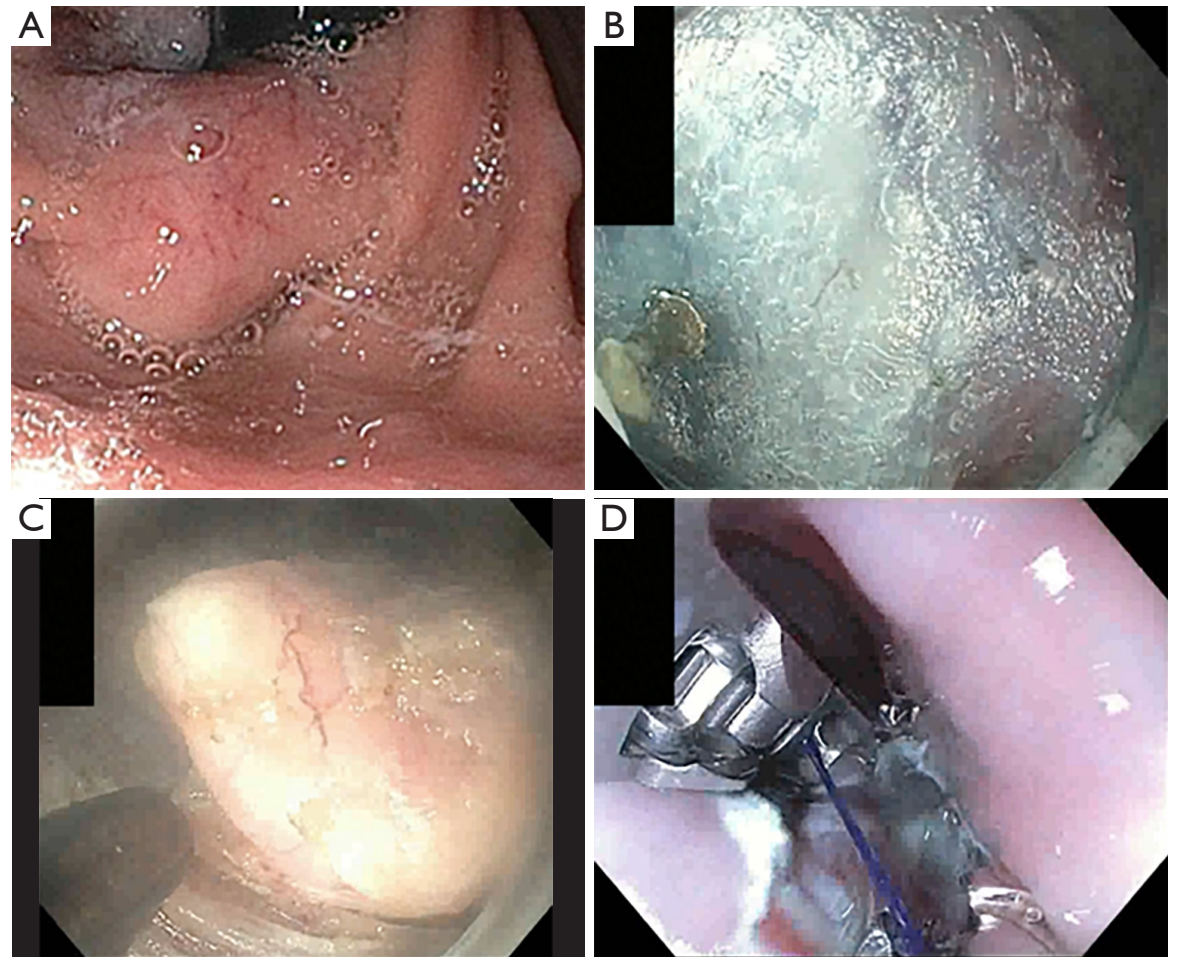

Figure 3 Submucosal tunneling endoscopic resection. (A) Endoscopy showing the submucosal lesion in the fundus; (B) submucosal tunneling with injection of methylene blue as well as electrosurgical knife; (C) the lesion being dissected from the deeper layer of muscularis propria; (D) closure of the defect with endoscopic suturing.

group had a similar event. The STER technique also allows for a better visual field and precise hemostasis, while in the EFTR group hemostasis may be more difficult. However, it is important to keep in mind that location of the lesion may ultimately determine what technique is chosen. A submucosal tunnel is not always easy to create in certain areas of the stomach which limits the ability to use STER for removal of a lesion, while EFTR can be used in all areas so may be a more favorable options in certain instances (60).

\section{Combined surgical and endoscopic approaches}

Size of the lesions remains an obstacle for these new endoscopic approaches. As a result, combined techniques such as laparoscopic and endoscopic cooperative surgery (LECS) have been developed to achieve better success. The procedure was initially introduced by Hiki et al. where 7 patients underwent LECS with successful removal of the entire tumor without significant bleeding and uncomplicated postoperative course (62). A more recent study evaluated 10 patients who underwent LECS with an average tumor size of $5.6 \mathrm{~cm}$ and $\mathrm{R} 0$ resection was achieved in all patient with no significant adverse events (63). Multiple modified LECS procedures have been developed in recent years. While the details of these combination procedures are beyond the scope of this paper, further studies regarding the safety and efficacy of these procedures will lead to innovative combined therapeutic options for these lesions.

\section{Conclusions}

Endoscopic resection is a constantly evolving field. Great advances have been made over the last decade in development of techniques such as ESD, EFTR, and STER. These techniques provide a less invasive approach for management of subepithelial lesions when compared to surgery, while still achieving clear resection margins. Size of the lesions as mentioned above, continues to be a limiting factor for many of these endoscopic approaches, although there have been some advancements made with combined endoscopic and laparoscopic approaches for larger lesions. 
Additionally, new technology and devices for resection and closure will help refine current techniques while also aiding in developing new approaches.

\section{Acknowledgments}

Funding: None.

\section{Footnote}

Provenance and Peer Review: This article was commissioned by the Guest Editor (Amy Tyberg) for the series "Innovation in Endoscopy" published in Translational Gastroenterology and Hepatology. The article has undergone external peer review.

Conflicts of Interest: Both authors have completed the ICMJE uniform disclosure form (available at https://tgh.amegroups. com/article/view/10.21037/tgh-2020-10/coif). The series "Innovation in Endoscopy" was commissioned by the editorial office without any funding or sponsorship. The authors have no other conflicts of interest to declare.

Ethical Statement: The authors are accountable for all aspects of the work in ensuring that questions related to the accuracy or integrity of any part of the work are appropriately investigated and resolved.

Open Access Statement: This is an Open Access article distributed in accordance with the Creative Commons Attribution-NonCommercial-NoDerivs 4.0 International License (CC BY-NC-ND 4.0), which permits the noncommercial replication and distribution of the article with the strict proviso that no changes or edits are made and the original work is properly cited (including links to both the formal publication through the relevant DOI and the license). See: https://creativecommons.org/licenses/by-nc-nd/4.0/.

\section{References}

1. Miettinen M, Sobin LH, Lasota J. Gastrointestinal stromal tumors of the stomach: a clinicopathologic, immunohistochemical, and molecular genetic study of 1765 cases with long-term follow-up. Am J Surg Pathol 2005;29:52-68.

2. Shen $\mathrm{C}$, Chen H, Yin Y, et al. Endoscopic versus open resection for small gastric gastrointestinal stromal tumors: safety and outcomes. Medicine (Baltimore) 2015;94:e376.
3. Feng F, Liu Z, Zhang X, et al. Comparison of Endoscopic and Open Resection for Small Gastric Gastrointestinal Stromal Tumor. Transl Oncol 2015;8:504-8.

4. Wang L, Fan CQ, Ren W, el al. Endoscopic dissection of large endogenous myogenic tumors in the esophagus and stomach is safe and feasible: a report of 42 cases. Scand J Gastroenterol 2011;46:627-33.

5. Yamamoto H, Koiwai H, Yube T, et al. A successful singlestep endoscopic resection of a 40 millimeter flat-elevated tumor in the rectum: endoscopic mucosal resection using sodium hyaluronate. Gastrointest Endosc 1999;50:701-4.

6. Ono H. Endoscopic submucosal dissection for early gastric cancer. Chin J Dig Dis 2005;6:119.

7. Gotoda T. A large endoscopic resection by endoscopic submucosal dissection procedure for early gastric cancer. Clin Gastroenterol Hepatol 2005;3:S71-3.

8. Yamamoto H, Yahagi N, Oyama T. Mucosectomy in the colon with endoscopic submucosal dissection. Endoscopy 2005;37:764.

9. Oyama T, Tomori A, Hotta K, et al. Endoscopic submucosal dissection of early esophageal cancer. Clin Gastroenterol Hepatol 2005;3:S67-70.

10. Fujishiro $M$, Yahagi N, Nakamura $M$, et al. Successful outcomes of a novel endoscopic treatment for GI tumors: endoscopic submucosal dissection with a mixture of highmolecular-weight hyaluronic acid, glycerin, and sugar. Gastrointest Endosc 2006;63:243.

11. Cao Y, Liao C, Tan A, et al. Meta-analysis of endoscopic submucosal dissection versus endoscopic mucosal resection for tumors of the gastrointestinal tract. Endoscopy 2009;41:751.

12. He Z, Sun C, Wang J, et al. Efficacy and safety of endoscopic submucosal dissection in treating gastric subepithelial tumors originating in the muscularis propria layer: a single-center study of 144 cases. Scand J Gastroenterol 2013;48:1466-73.

13. Park JC, Lee SK, Seo JH, et al. Predictive factors for local recurrence after endoscopic resection for early gastric cancer: long-term clinical outcome in a single-center experience. Surg Endosc 2010;24:2842.

14. Takahashi H, Arimura Y, Masao H, et al. Endoscopic submucosal dissection is superior to conventional endoscopic resection as a curative treatment for early squamous cell carcinoma of the esophagus (with video). Gastrointest Endosc 2010;72:255.

15. He Z, Sun C, Zheng Z, et al. Endoscopic submucosal dissection of large gastrointestinal stromal tumors in the esophagus and stomach. J Gastroenterol Hepatol 
2013;28:262-7.

16. Rajan E, Wong Kee Song LM. Endoscopic Full Thickness Resection. Gastroenterology 2018;154:1925-1937.e2.

17. Pimentel-Nunes P, Mourão F, Veloso N, et al. Long-term follow-up after endoscopic resection of gastric superficial neoplastic lesions in Portugal. Endoscopy 2014;46:933-40.

18. Liu Q, Ding L, Qiu X, et al. Updated evaluation of endoscopic submucosal dissection versus surgery for early gastric cancer: A systematic review and meta-analysis. Int J Surg 2020;73:28-41.

19. Ishihara R, Iishi H, Uedo N, et al. Comparison of EMR and endoscopic submucosal dissection for en bloc resection of early esophageal cancers in Japan. Gastrointest Endosc 2008;68:1066-72.

20. Urabe Y, Hiyama T, Tanaka S, et al. Advantages of endoscopic submucosal dissection versus endoscopic oblique aspiration mucosectomy for superficial esophageal tumors. J Gastroenterol Hepatol 2011;26:275-80.

21. Barret M, Cao DT, Beuvon F, et al. Endoscopic submucosal dissection for early Barrett's neoplasia. United European Gastroenterol J 2016;4:207-15.

22. Yang D, Coman RM, Kahaleh M, et al. Endoscopic submucosal dissection for Barrett's early neoplasia: a multicenter study in the United States. Gastrointest Endosc 2017;86:600-7.

23. Stavropoulos SS, Gurram KC, Bhumi S, et al. Tu1259 ESD for Early Esophageal Cancer at a Western Center: Practice Makes Perfect. Gastrointest Endosc 2017;85:AB605-AB606.

24. Akintoye E, Kumar N, Aihara H, et al. Colorectal endoscopic submucosal dissection: a systematic review and meta-analysis. Endosc Int Open 2016;4:E1030-44.

25. Kantsevoy SV, Adler DG, Conway JD, et al. Endoscopic mucosal resection and endoscopic submucosal dissection. Gastrointest Endosc 2008;68:11-8.

26. Tanaka S, Oka S, Kaneko I, et al. Endoscopic submucosal dissection for colorectal neoplasia: possibility of standardization. Gastrointest Endosc 2007;66:100-7.

27. Lian J, Chen S, Zhang Y, et al. A meta-analysis of endoscopic submucosal dissection and EMR for early gastric cancer. Gastrointest Endosc 2012;76:763-70.

28. Goto O, Shimoda M, Sasaki M, et al. Potential for peritoneal cancer cell seeding in endoscopic full-thickness resection for early gastric cancer. Gastrointest Endosc 2018;87:450-6.

29. Feng Y, Yu L, Yang S, et al. Endolumenal endoscopic full-thickness resection of muscularis propria-originating gastric submucosal tumors. J Laparoendosc Adv Surg Tech
A 2014;24:171-6.

30. Huang LY, Cui J, Lin SJ, et al. Endoscopic full-thickness resection for gastric submucosal tumors arising from the muscularis propria layer. World J Gastroenterol 2014;20:13981-6.

31. Liu BR, Song JT. Submucosal Tunneling Endoscopic Resection (STER) and Other Novel Applications of Submucosal Tunneling in Humans. Gastrointest Endosc Clin N Am 2016;26:271-82.

32. Sarker S, Gutierrez JP, Concil L, et al. Over-the scope clip-assisted method for resection of full-thickness submucosal lesions of the gastrointestinal tract. Endoscopy 2014;46:758-61

33. Al-Bawardy B, Rajan E, Wong Kee Song LM. Over the scope clip assisted full thickness resection of epithelial and subepithelial lesions. Gastrointest Endosc 2017;85:1087-92.

34. Schmidt A, Meier B, Caca K. Endoscopic full-thickness resection: Current status. World J Gastroenterol 2015;21:9273-85.

35. Backes Y, Kappelle WFW, Berk L, et al. Colorectal endoscopic full-thickness resection using a novel, flatbase over-the-scope clip: a prospective study. Endoscopy 2017;49:1092-7.

36. Fähndrich M, Sandmann M. Endoscopic full-thickness resection for gastrointestinal lesions using the over-thescope clip system: a case series. Endoscopy 2015;47:76-9.

37. Schmidt A, Benya T, Schumacher B, et al. Colonoscopic full thickness resection using an over-the-scope device: a prospective multicenter study in various indications. Gut 2018;67:1280-9.

38. Bauder M, Schmidt A, Caca K. Endoscopic full-thickness resection of duodenal lesions-a retrospective analysis of 20 FTRD cases. United European Gastroenterol J 2018;6:1015-21

39. Hu JW, Zhang C, Chen T, et al. Submucosal tunneling endoscopic resection for the treatment of rectal submucosal tumors originating from the muscular propria layer. J Cancer Res Ther 2014;10 Suppl:281-6.

40. Jain D, Mahmood E, Desai A, et al. Endoscopic full thickness resection for gastric tumors originating from muscularis propria. World J Gastrointest Endosc 2016;8:489-95.

41. Yang F, Wang S, Sun S, et al. Factors associated with endoscopic full-thickness resection of gastric submucosal tumors. Surg Endosc 2015;29:3588-93.

42. Joo MK, Park JJ, Kim H, et al. Endoscopic versus surgical resection of GI stromal tumors in the upper GI tract. 
Gastrointest Endosc 2016;83:318-26.

43. Wang H, Feng X, Ye S, et al. A comparison of the efficacy and safety of endoscopic full-thickness resection and laparoscopic-assisted surgery for small gastrointestinal stromal tumors. Surg Endosc 2016;30:3357-61.

44. Zhou PH, Yao LQ, Qin XY, et al. Endoscopic fullthickness resection without laparoscopic assistance for gastric submucosal tumors originated from the muscularis propria. Surg Endosc 2011;25:2926-31.

45. Endo $M$, Inomata $M$, Terui $T$, et al. New endoscopic technique to close large mucosal defects after endoscopic mucosal resection in patients with gastric mucosal tumors. Dig Endosc 2004;16:372-5.

46. Ye LP, Yu Z, Mao XL, et al. Endoscopic full-thickness resection with defect closure using clips and an endoloop for gastric subepithelial tumors arising from the muscularis propria. Surg Endosc 2014;28:1978-83.

47. Kobayashi M, Sumiyama K, Ban Y, et al. Closure of iatrogenic large mucosal and full-thickness defects of the stomach with endoscopic interrupted sutures in in vivo porcine models: are they durable enough?. BMC Gastroenterol 2015;15:5.

48. Stavropoulos SN, Modayil R, Friedel D. Current applications of endoscopic suturing. World J Gastrointest Endosc 2015;7:777-89.

49. Guo J, Sun B, Sun S. Endoscopic puncture suture device to close gastric wall defects after full thickness resection: a porcine study. Gastrointest Endosc 2017;85:447-50.

50. Xu MD, Cai MY, Zhou PH, et al. Submucosal tunneling endoscopic resection: a new technique for treating upper GI submucosal tumors originating from the muscularis propria layer (with videos). Gastrointest Endosc 2012;75:195-9.

51. Li QL, Chen WF, Zhang C, et al. Clinical impact of submucosal tunneling endoscopic resection for the treatment of gastric submucosal tumors originating from the muscularis propria layer (with video). Surg Endosc 2015;29:3640-6.

52. Wang H, Tan Y, Zhou Y, et al. Submucosal tunneling endoscopic resection for upper gastrointestinal submucosal tumors originating from the muscularis propria layer. Eur J Gastroenterol Hepatol 2015;27:776-80.

53. Tan Y, Lv L, Duan T, et al. Comparison between submucosal tunneling endoscopic resection and videoassisted thoracoscopic surgery for large esophageal leiomyoma originating from the muscularis propria layer. Surg Endosc 2016;30:3121-7.

54. Du C, Ma L, Chai N, et al. Factors affecting the effectiveness and safety of submucosal tunneling endoscopic resection for esophageal submucosal tumors originating from the muscularis propria layer. Surg Endosc 2018;32:1255-64.

55. Dellatore P, Bhagat V, Kahaleh M. Endoscopic Full Thickness Resection versus Submucosal Tunneling Endoscopic Resection for Removal of Submucosal Tumors: a Review Article. Transl Gastroenterol Hepatol 2019;4:45.

56. Lv XH, Wang CH, Xie Y. Efficacy and safety of submucosal tunneling endoscopic resection for upper gastrointestinal submucosal tumors: a systematic review and meta-analysis. Surg Endosc 2017;31:49-63.

57. Chen T, Zhou PH, Chu Y, et al. Long-term Outcomes of Submucosal Tunneling Endoscopic Resection for Upper Gastrointestinal Submucosal Tumors. Ann Surg 2017;265:363-9.

58. Du C, Linghu E. Submucosal Tunneling Endoscopic Resection for the Treatment of Gastrointestinal Submucosal Tumors Originating from the Muscularis Propria Layer. J Gastrointest Surg 2017;21:2100-9.

59. Ye LP, Zhang Y, Mao XL, et al. Submucosal tunneling endoscopic resection for small upper gastrointestinal subepithelial tumors originating from the muscularis propria layer. Surg Endosc 2014;28:524-30.

60. Tan Y, Tang X, Guo T, et al. Comparison between submucosal tunneling endoscopic resection and endoscopic full-thickness resection for gastric stromal tumors originating from the muscularis propria layer. Surg Endosc 2017;31:3376-82.

61. Duan TY, Tan YY, Wang XH, et al. A comparison of submucosal tunneling endoscopic resection and endoscopic full-thickness resection for gastric fundus submucosal tumors. Rev Esp Enferm Dig 2018;110:160-5.

62. Hiki N, Yamamoto Y, Fukunaga T, et al. Laparoscopic and endoscopic cooperative surgery for gastrointestinal stromal tumor dissection. Surg Endosc 2008;22:1729-35.

63. Mahawongkajit P, Chanswangphuvana P. Laparoscopyassisted endoscopic full-thickness resection of upper gastrointestinal subepithelial tumors: A single-center early experience. Mol Clin Oncol 2020;12:461-7.

doi: $10.21037 /$ tgh-2020-10

Cite this article as: Dalal I, Andalib I. Advances in endoscopic resection: a review of endoscopic submucosal dissection (ESD), endoscopic full thickness resection (EFTR) and submucosal tunneling endoscopic resection (STER). Transl Gastroenterol Hepatol 2022;7:19. 